\title{
MANAGEMENT AND INNOVATION IN ENTREPRENEURIAL UNIVERSITIES FROM THE CULTURAL SECTOR
}

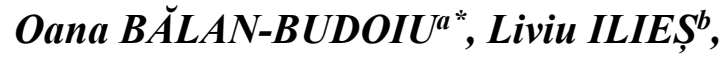 \\ ${ }^{a}$ ANMGD, Cluj-Napoca, Romania \\ ${ }^{b} U B B-F S E G A$ Cluj-Napoca, Romania
}

\begin{abstract}
In very many areas, the global cultural sector is currently experiencing a major economic crisis, caused mainly by the technology lag that has steadily increased in the past years. The possible elimination of certain art fields which cannot keep up with the dynamics of consumption markets will induce a series of adverse effects most acutely perceivable on the socio-educational level. This study defines the model of the "executive innovation" in functional and conceptual terms, being applicable in the sphere of art universities. We shall configure a series of entrepreneurial prototypes specific to higher education institutions meant to formulate an adequate position in relationship to the tendencies of the future.

We believe that, in order to innovate the top-level management in culture, we must identify and implement good managerial practices, based on the expertise of researchers with a high academic level, provide scientific arguments, achieve a realistic strategic plan that can produce a viable transformation leading towards an open, interactive system based on innovation and adapted to the times we live in.
\end{abstract}

KEYWORDS: benchmarketing, innovation, entrepreneurship, strategic management, university.

\section{INTRODUCTION:}

A people's national culture has a major impact on a country's economy (Greif, 1994), perpetuating sets of values and behaviours with positive effects on sustainable developments. Society's dynamization through culture, its modernization but particularly its education through art have become factors of interest for those responsible for ensuring a certain life quality level all over the world (Roșca, 2020). It is desirable to achieve community evolution by enriching national cultural capitals, by moulding a people's identity and standardizing certain value measures, which should determine individuals to revise their consumption attitudes in favour of a superior social environment. We can notice that higher education institutions have engaged in a race to find ideas that can keep up with the accelerated and permanent technological innovations. The bottom line for our present life is "flexibility", both subjective and objective, which is invoked by all means available and brings with it, more and more, an emergence of scientific compromises. Any university oriented unidirectionally towards academic performance must, according to these new norms, adapt in order to stay relevant for the "mass" society, being required to shift its position from "supreme educational authority responsible for the individuals" progress" into a "service supplier" subordinated to community's needs. The concern for the external environment, for the society that requires the educational services is now the main element that can reduce the value disparity between supply and demand. It is noticeable that the maintenance of scientific performances is feasible solely on condition that the environment, situated outside of the academic communities, accept all higher education interventions, which must be facilitated by identifying and

\footnotetext{
* Corresponding author. E-mail address: oana.balan@amgd.ro
} 
employing those instruments that provide a supplementary factor of mutual and anticipated "adjustment" and "familiarization". Concretely, it is desirable that society may also be brought to a point at which it understands and is willing to access higher education services, regardless of the field. On the other hand, higher education institutions are already engaged in a long-lasting "adaptation" which compresses and simplifies teaching and learning procedures in favour of individuals. The major problem raised by this situation is: if the university must make a permanent effort to "adapt", then who is left in charge of "shaping the community" so that it can also activate the dynamic profile that enables it to increase value? How do we determine society to progress as well, so as to approach the levels the university wants to offer?

We think the critical point of this imbalance was generated after the adherence to the "Bologna Process" (1999), through a profound reform that brought significant long-term transformations for higher education institutions. Nevertheless, not all universities managed to thoroughly implement the "social dimension" in their curricula in order to create new relevant, open, cohesive and inclusive programs with economic potential for common people.

Some domains are still making efforts to find the prototype of services required on the market or the means by which to determine society to take a leap of faith towards certain types of training. One of them is the domain of the arts, particularly that part of it represented by music universities. The considerable progress attained by the arts and music universities over the past years brought with it the shaping of a new qualifications framework that implicitly appealed to an enlarged access to education, to adopting a spirit open to development and modernization. Besides the domain's basic knowledge, many universities found themselves constrained to elaborate managerial strategies, politics and practices that were both efficacious and appropriate, to build sets of programs with transversal roles in order to ensure the active transfers of students into society and their integration on a more general labour market, supporting the very creation of new employment opportunities.

Music higher education in Romania is more than two centuries old. There is quite a large number of Romanian higher education institutions that produce an annual average of 1000 to 1200 graduates. The volatile public system relying heavily on permanent employment contracts makes it often impossible for these graduates to enter the labour market. The cultural studies of the last 20 years continuously raise the issue of the impact that artistic education has on society. The analyses conducted up to this moment (Rager, 2008) start from the model of the dynamics of the dialogue between community and $20^{\text {th }}$ century art, particularly in the American space. Visible endeavours meant to quantify the range of issues specific to our times are also discernible in Australia (Barton, 2018; Gaunt, 2013; Kelly 2016), referring to studies of artistic anthropology developed in mid $20^{\text {th }}$ century (Merriam, 1964), where they insist on the potential of "mass" individuals to learn new behaviours and concepts. Less visible in the literature, but amply approached as a strategy of managerial progress, the preoccupation to identify the social relevance of arts universities has been the topic of several international projects, with which over 100 higher education arts institutions lined up worldwide. In this direction one of the most significant contributions was brought by "Polifonia"[1], a pilot project that investigated the level of openness that European academic institutions in the music field show towards the implementation of entrepreneurial programmes:

"Higher arts education institutions have not responded adequately to new career challenges. There is a mismatch between training and demands of the labor market. Today, entrepreneurial and arts management skills are a basic necessity for all future artists." ${ }^{2]}$ Research extending over a period of several years has shown that there are some systems, such as the Anglo-Saxon education, which starts building an entrepreneurial thinking at a very early stage, an aspect which considerably influences the attitude of young adults when it comes to practicing or not practicing artistic entrepreneurship. In the field of arts, for instance, primary and lower secondary schools in Northern Europe encourage students to take part in business enterprises with a high degree of responsibility, offering interdisciplinary courses in the field of financial education and personal development designed for children aged 5 to 18. They are co-opted in business incubators and are entrusted responsibilities in the administration of specific management issues on various levels. It is therefore 
no wonder that Great Britain, Ireland and the North-European countries have moved ahead, being among the most developed countries in the field of entrepreneurial-musical higher education. There have also been important evolutions in the institutional restructuring of the cultural-musical universities from other European countries, which evinces a serious interest in integrating additional disciplines that may provide this type of entrepreneurial training.

\section{THEORETICAL FRAMEWORK}

The literature describes educational entrepreneurship as a global flexible force capable to improve the act of teaching through uniqueness and by improving many peoples' standard of living (Sarasvathy, 2011; Patzelt, 2011).

The emergence of entrepreneurship was associated to the field of business (Druker, 1985; Becker \& Knudsen, 2002), lining up in the past years with the social and educational spheres (Bornstein, 2004; Hess, 2006). By “entrepreneurial institution" we understand nowadays an entity that provides competitive major subjects, which are potentially profitable after graduation.

The $21^{\text {st }}$ century entrepreneur exploits the levers that can generate profit, permanently identifying new opportunities to develop them, taking risks and making the best of the available resources in order to obtain success (Knight, 1921; McClelland, 1961). According to this theory, the contemporary educational economy relies on flexible and adaptable knowledge.

Historically speaking, entrepreneurship has been interpreted and reinterpreted, continuously changing its conceptualization. If we pay attention to the theoretical definitions alone, regarding the entrepreneur as an enterpriser (a person working in an organization), then its history may begin with the first forms of economy in the Mesopotamia of year 3500 B.C. (Landes, Mokyr \& Baumor, 2010). The empirical period lasted until the $16^{\text {th }}$ century, when the French literature started to associate entrepreneurs with those leaders that possessed particular abilities, being willing to risk individuals carrying huge responsibility, commissioned to organize military expeditions, who accepted the task of designing and building fortifications meant to protect.

In a parallel, metaeconomic approach, the end of the $18^{\text {th }}$ century brought to light a new theory, in which entrepreneurship relied on a set of more refined attitudes and abilities, such as creativity, initiative, vision, orientation towards change: "so great and so numerous that very few people can exhibit them all in a very high degree" which favour the provision of capital (Hoselitz, 1984), placing it closer to a rather modern culture of management that focuses on guaranteeing new production plans and, implicitly, a certain economic growth.

The classical school (J. Say, 1800) also brought the enterpriser's image closer to that of today's manager, adding to it those complex, transversal competencies that investors should possess nowadays: to acquire information of legal and financial origin, to be capable to attract funds and coordinate businesses optimally, winning any competition at any price. This vision returns to the ancient concepts where the role of production and distribution leader could be found among the Aristotelian principles, seen as a phenomenon with two opposed poles of the gain-or-loss type,

"something or somebody robbed, in favour of a benefit on the other side, that of the competition" . Schumpeter (1934) define entrepreneurship as a set of general activities, with a leading role, in which the enterpriser seeks to derive profit from exploiting opportunities, from taking advantage of the market's flaws. In relationship to risk management, McClelland and Knignt (1921) stress that entrepreneurs are motivated by a desire to stand out which, as a rule, is stronger than the possible uncertainties that may emerge in production processes.

The most important representative of the neoclassical school, Alfred Marshall (1922) insisted in his definitions on the technological innovations and the adaptability, which can highlight and coagulate a distinct profile of the entrepreneur. He emphasizes the importance of his courage in starting new and profitable actions, of his capacity to identify market opportunities, to anticipate and act in accordance with the flow of demand. 
Van Praag (2005) asserts that the innovative spirit is the fundamental cause of any entrepreneurial venture, while processes that lack entrepreneurs are static and vulnerable when faced with changes. A major contribution to the entrepreneurial theory was also brought by Frank Knight, who built his entire system starting from the "state of uncertainty". In contradiction to the principles of the neoclassical school, Knight asserts that man cannot have all the information necessary in order to make decisions in safe circumstances. As such, entrepreneurs can be considered successful only in uncertain circumstances. In line with this, the authors of the last decades see the connection between risk and success as the key to the entrepreneurial concept. According to these researches, the uncertainty on which the entrepreneur builds their activities is omnipresent and extends across several levels (Istocescu, 2003):

$\checkmark$ Minor, controllable uncertainties - when the entities limit the flow of changes, innovations being scarce;

$\checkmark$ High, strong uncertainties, with unpredictable variations and situations which often lead to the disappearance of the entities;

$\checkmark$ Uncontrollable uncertainties, where there is no calculation in relationship to profit and the investment model is done by imitation rather than by reasoning.

Returning to the traditional and neoclassical concepts, we wish to stress the fact that they tended to ignore the entrepreneur as a person, focussing on the growth of capital and the economic development. Nowadays entrepreneurs have a major importance particularly for the influence they can have on the market, as they can stimulate and create workplaces. From the social perspective as well, the entrepreneur can provoke "domino"-like reactions in which, through their actions, they can become a model for others and thus generate a "chain"-like innovation system.

Summarizing the theories described, we can assert that the ideal profile of the "entrepreneur" is represented nowadays by that dynamic, practical system endowed with strategic intelligence, independent and dominant, speculative, willing to accept risks in order to produce new products and services (Istocescu, 2003). Along with these features, an essential component of the entrepreneurial conduct is the "realistic vision", which regards as compulsory, with the role of rendering efficient the action plan and the perspectives of implementation.

The actual tendencies in the field of science concentrate on introducing entrepreneurial elements in order to adjust the imbalance between the scientific "market supply" and the "desires of the researchers-consumers". They foresee that the product industry will address the general population or will try to include a larger number of components in order to satisfy individuals on multiple levels.

Entrepreneurship is the instrument of sustainability, of improving the efficiency of processes and the development of services through managerial innovation and creativity. The new ideas, the modern products and services have no value and are not utile until they are truly useful in real life the reason why a concept like this cannot exist in theory alone. The definition of entrepreneurship must include the position of society in relationship to the ideas that it generates, the consumers' attitudes, the economic and legal systems, all these being fundaments that make the science of management specific and increasingly complex in our times.

For the purpose of entrepreneurial education, the institutions can be considered mobile agents, catalysers which can extend its applicability from the general to the individual level, changing mentalities and ensuring the connection between theory and practice (Ilieș et al., 2006).

Successful universities will have to intensify their collaboration with the labour market in order to come up with suitable offers, to design the ideal profile that should be entirely compatible with the labour market demands.

Extrapolating for the environment of education, we think that a higher education institution can be regarded as entrepreneurial if it is open to the needs of the students, the labour market, nonconformist, dynamic and ready for innovation, accepting risk as an integral part of the modernization process. 
In the academic field, the entrepreneurial concept is closely linked to creativity and innovation, to creating that circuit that goes beyond the conventional practices and knowledge, centred on the needs and developments of individuals and the market demand. The mutation in the way people reason, that entrepreneurship appeals to, is generated by the interaction of supply and demand.

\section{PROBLEM AND METHODS}

The Romanian private cultural sector has remained relatively constant over the last ten years. What stands out is a tendency of small art companies (0-9 people) to act on the market and the lack of interest in selling symphonic music, as merely $1,8 \%$ of the registered companies deal with this specialized production as their object of activity. The large majority of commercial companies, which have achieved success in this field, deal with products meant for ambience, entertainment, and software. Thus, the Romanian national coefficient of absorption for the graduates of the cultural-musical universities into the system they were trained for is rather limited. According to Eurostat $^{[3]}$, on a worldwide level as well, the demands for musical products come mainly from producers of films, advertising, publicity, computer games and other categories, preponderantly in the digital area, which use music only secondarily, with the role of audio background. A fastgrowing industry that gains ground to the detriment of opera performances or symphonic concerts in philharmonics, weakening the utility of the education offered by the institutions specializing in musicology and professional music performance.

The pressure exerted by this reality upon the academic communities from the field of arts forces the system to project new prototypes that may also justify, over time, the necessity of preserving this educational system. We consider the following to be necessary to this end:

$\checkmark$ New niches of research in creative industries;

$\checkmark$ Setting up musical entrepreneurship incubators that can shape, develop and coordinate the new initiatives of students and graduates, as a reaction to the changes in the environment;

$\checkmark$ Conducting market analyses and case studies in order to devise curricular structures linked directly to the demands of the consumption market;

$\checkmark$ Possibilities of professional reorientation for the students and graduates of conservatoires, by short-term domain of expertises

$\checkmark$ Training the teaching staff to implement entrepreneurial models by offering interdisciplinary courses and learning resources;

$\checkmark$ Including sub-domains as a reaction to the market demands: mediation and children's concerts, film music composition, music for advertising, music for educational software and computer games, courses in lutherie, construction and tuning of musical instruments, project management, marketing and promotional strategies for the field of art music, working as artists' agents;

$\checkmark$ Stimulation of musical business ideas through contests for artistic start-ups and offering stimulating prizes.

Starting from the presumption that the young musicians are aware of the importance of these interventions, from January to June 2020 we conducted two sessions of observational research, with two groups of subjects, students and alumni of universities in the cultural-artistic field.

The model chosen for the research relies on the total quality management science, which implies the internalization of the "client-supplier" relationship in terms of a process-based approach. This model resorts to prioritizing the causes that produce the imbalances found in the managerial system, identifying the elements that can help to re-balance and progress, focusing on the consumer satisfaction (Ilieș \& Crisan 2011).

Based on the conceptual elements collected from the literature and the international practice, we applied two questionnaires for two sample groups

- E1: students of the cultural-musical universities in Romania

- E2: young graduates (alumni) of artistic education,

both sample groups consisting of respondents aged 18 to $40+$. 
For the first questionnaire (named "The efficiency of study programmes in cultural-musical universities in relationship to the labour market") we collected a number of 253 responses, of which $83 \%$ from undergraduate students, 8,3\% from doctoral students and 8,7\% from master's students. Given the yearly graduation rate in the field of arts education, calculated in relationship to an average of 1000 to 1200 people, we assess that the impact ratio of $21-25 \%$ falls into the "superior" control category.

In parallel with the survey addressing students, in order to accomplish a comparative research, we used a similar questionnaire for graduates (secondary control group), having the same purpose of measuring the efficiency of study programmes in relationship to the labour market. We collected a total of 115 responses, $17 \%$ from alumni aged 22 to $25,31 \%$ aged 25 to $30,15 \%$ aged 30 to $35,9 \%$ aged 30 to 40 , and $28 \%$ with ages over 40 , all employees of public and private institutions from the field of arts. Compared to the data percentage collected from sample group 1, the inquiry conducted for sample group 2 is qualitatively inferior, reaching a control percentage of $2,57 \%$. Nevertheless, the disadvantage of the data collection for sample group 2 can be overcome and it may be included in the control category "sufficient" for the comparative analysis of the data type proposed by the questionnaires.

Relying on extant theories and studies, our research involved a „parametric test” based on three confirmatory hypotheses:

- Hypothesis 1: the students' internships in institutions or companies (specific to their area of professional training) will contribute significantly to developing an entrepreneurial attitude

- Hypothesis 2: the „market analyses” for the reconstruction of study programmes (curriculums) will increase the managerial efficiency in music universities

- Hypothesis 3: introducing new teaching goals, specific to personal development, critical thinking, self-marketing, elements of dialogue and knowledge of the beneficiaries' behaviour will lead towards educating an entrepreneurial style

The independent variables chosen for this research are defined by the causes, the factors and the circumstances in which the subjects were educated and by the environment in which they perform their activity, along with a set of dependent variables that observe the effects and the outcomes in order to develop an entrepreneurial attitude.

\section{RESULTS}

Starting from the analysed models of entrepreneurial education, one of our research's presumptions was that young people are willing to have the practical experiences of beginning to work in enterprises during their university education, as an essential aspect for their professional development. Of all the respondents, only $7,1 \%$ rejected the idea of an internship integrated in the curriculum, regardless of the constraints this would involve (figure 1). We can infer from this that a first element of entrepreneurial attitude is already present and can be employed in favour of an educational reform, that would increase the degree of community relevance in the cultural sector.
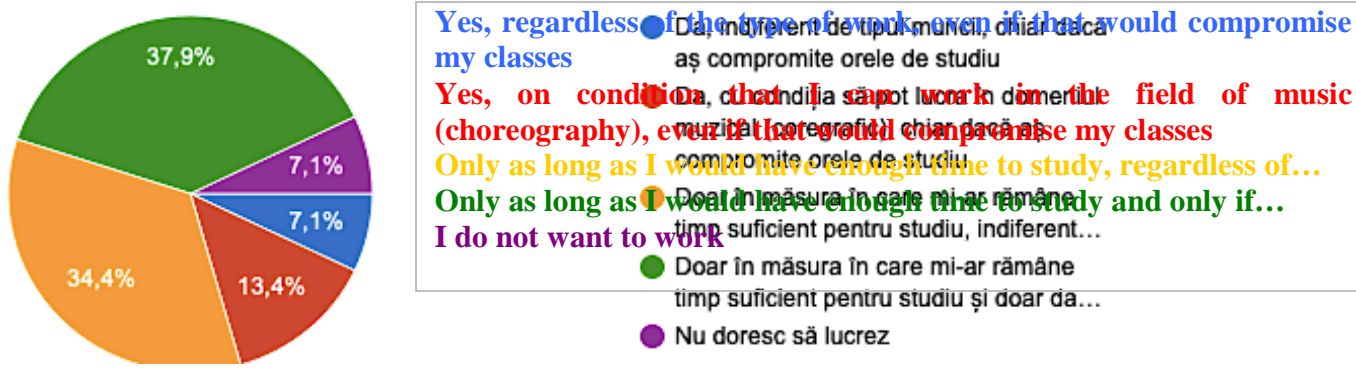

Figure 1. The level of students' availability for internships 
Another defining aspect for the „entrepreneurial universities model” requires the integration of the consumers' feedback as an integral part of the strategic developments. In our case, consulting the client-students in the processes that aim to modernize curricula and ensure an efficient connection to the labour market should test the viability of the educational offers. As such, the survey resorted to a design exercise, asking students to prospect the ideal structure of the university curricula so as to answer the real needs that they will be confronted with after graduation.
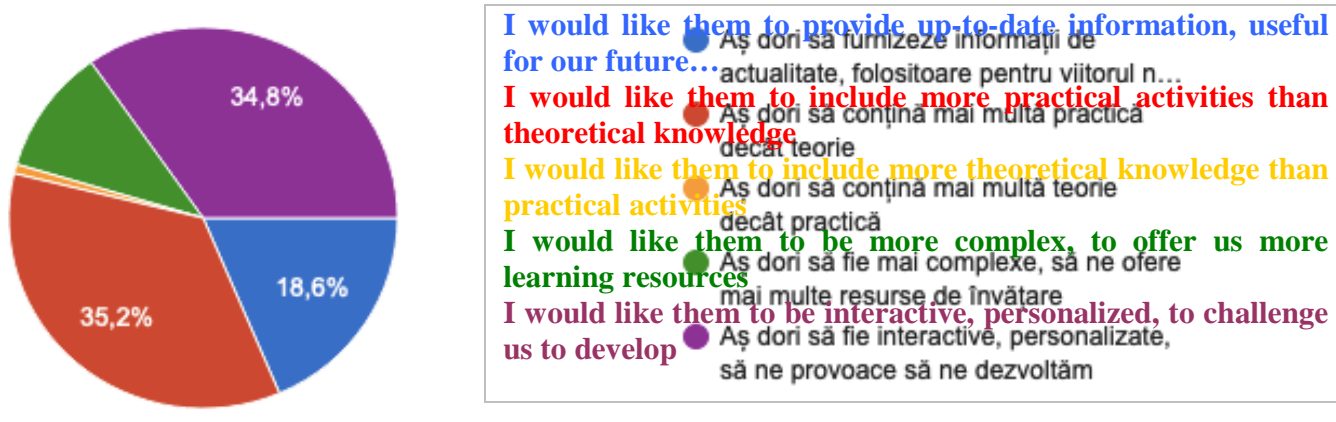

Figure 2. Model of cultural-entrepreneurial training

The results show that subjects expect a type of training structured into interactive courses preponderantly practical, which should stimulate and focus on productive majors faithful to the profiles of consumption markets. The highest percentage of the respondents would like to learn disciplines that would challenge them to develop and that will help strength the relationship between them and their potential employers.

Going forward towards the testing of entrepreneurial prototypes, we measured the respondents' availability to develop those behaviours of a "proactive-entrepreneurial" type. We checked the degree of the rationalization of their role on the consumption market, through the receptivity for and the openness to the initiation and coordination of cultural start-ups.

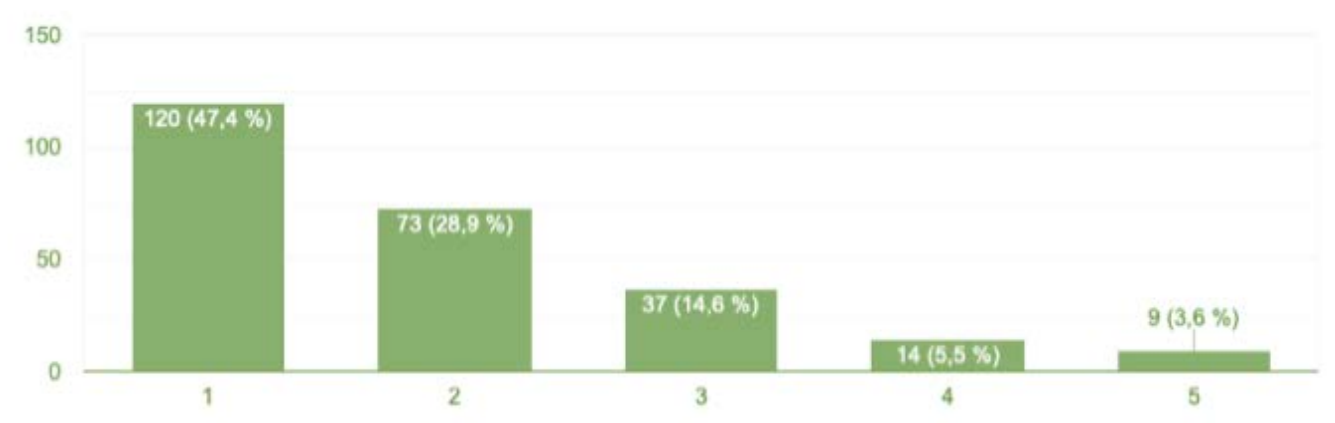

Figure 3. Measuring the students' predisposition for the initiation of creative start-ups

In order to determine the dimensions of this aspect, we measured the subjects' entrepreneurial intuition by creating independent experimental variables, of an aleatoric nature, so as to check their predispositions for leadership, creativity, strategic thinking, opportunity, risk and assuming responsibility, which they are supposed to have acquired due to the impact of the socio-educational environment in which they grew up and developed. 


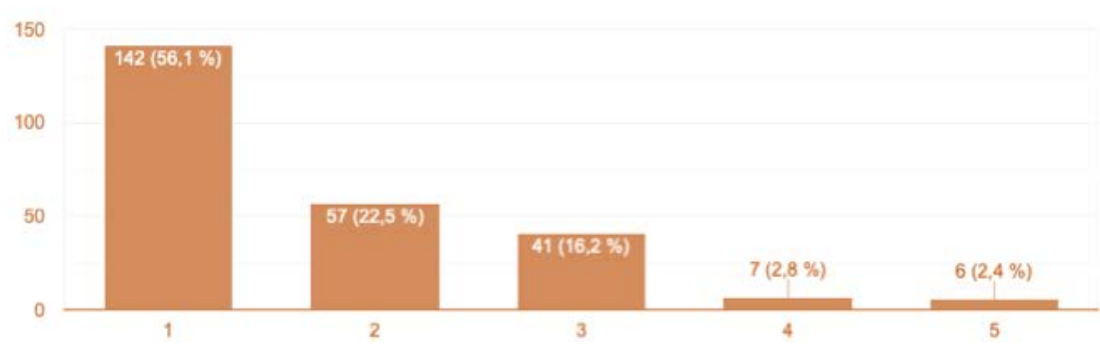

Figure 4. The entrepreneurial predisposition of the students from the cultural sector

The results show that $56,1 \%$ of the respondents exhibit the maximal speculative characteristics ideal for the entrepreneur's profile, highlighting intelligent, strategic mentalities favourable to the entrepreneurial visions described by the literary theory. The existence of this entrepreneurial psychological profile justifies the existence of new major areas of specialization - entrepreneurial ones - that have the potential to bring a significant contribution to the productivity of the Romanian cultural sector.

The data collected from Questionnaire 2 (graduates), which we used in order to analyse the comparative variables, before and after the contact to the labour market, confirms all three hypotheses, the necessity of introducing or extending internships during studies and the development of the educational-entrepreneurial profile being vital for the success in a cultural career. The subjects of survey 2, already employed in both the public and private sectors, complain of the lack of certain skills essential for their professional future. The list of the professional challenges that they had to manage and solve on their own is not at all negligible, since $67 \%$ of the alumni feel that it would have been helpful to have had access to employers and courses suitable for the professions they are currently pursuing such as volunteering programs or unpaid internships in cultural institutions.

The comparative analyses performed for the two categories of subjects confirm the idea that the university educational market from the Romanian cultural sector needs to be reoriented towards the real needs of the consumption market, as more than a half of the respondents in both control groups are convinced that this is one of the major problems that cultural universities in our country are faced with and that it impacts post-university careers in a negative manner.

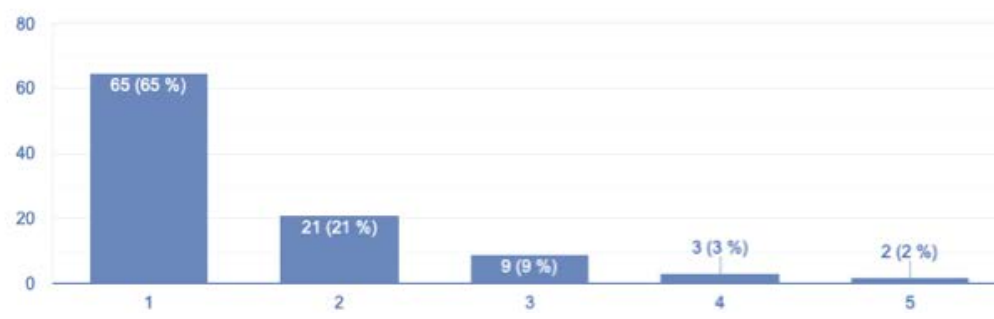

Figure 5 - The importance of a direct contract with the future employers already during the university studies

\section{CONCLUSIONS}

The prototypes of entrepreneurial education use formulas specific to change, dynamics, adaptability, elimination of discrepancies, taking of risks in management systems. Entrepreneurship in universities requires a redefinition, modernization and democratization of education from a superior level - that of the management - to the production and delivery of goods which are useful to society. 
This research focused on two aspects relevant for the strategic entrepreneurial management from the cultural sector:

- The analysis of the educational offers through the market filter, namely the imposition of a relationship of interdependence between the need for training expressed by cultural employers and the majors offered by the higher education institutions in the field of arts

- The encouragement of entrepreneurial predispositions in the students and the other final recipients of cultural products and services.

The data collected confirms that subjects of this research (students and alumni of the cultural sector) easily develop entrepreneurial skills, on condition that the higher education institutions provide the favourable framework for their developments. The first recommendation generated by the interpretation of the results is that universities curricular structures needs to be rethought in favour of a preponderantly practical type of education that can ensure a large number of bridges between the higher education institutions and the future employers: internship, volunteering, partnerships for the initiation and administration of start-ups and creative industries incubators. The curriculum reforms should also consider, to a significant extent, the position, the demand and the reaction of the client - students and alumni, who directly confront the pressures exerted by the outer environment. In this regard it is desirable that each curriculum reform should be anticipated by sessions designed to analyse the needs formulated by the beneficiaries of the educational offers. At the same time, it becomes essential to introduce teaching goals meant to stimulate creativity, initiative, entrepreneurial spirit, all of which led to the development of businesses and, implicitly, to an extension of cultural practices towards areas less exploited. The students and the alumni of universities from the cultural sector must be helped to create new jobs for themselves, to make themselves necessary in the community in which they choose to remain, to search for the freedom of being mobile, enterprising, adaptable, to take risks and be capable to stand their ground in a competitive system. The tendencies of the future require hybrid experts who know not only how to do their job well, but also how to use a set of complementary, innovative abilities through which to test new niches that are relevant to the society they live in.

\section{REFERENCES}

Becker, M., \& Knudsen, T. (2002). Schumpeter 1911: Farsighted Visions on Economic Development. The American Journal of Economics and Sociology, 61(2), 387-403. Retrieved July 20, 2020, from http://www.jstor.org/stable/3487788

Bornstein, D. (2004). How to Change the World: Social Entrepreneurs and the Power of New Ideas, Updated Edition. Oxford University Press.

Druker, F. P. (1985). Innovation and Entrepreneurship. Practice and principles, Routledge: London and New York

Greif, A. (1994). Cultural beliefs and the organisations of society: a historical and theoretical reflection on collectivist and individualist societies. The Journal of Political Economy. 102(5). 912-950.

Hess, R.F. (2006). Postabortion Research: Methodological and Ethical Issues. Qualitative Health Research. 16(4), 580-587. doi:10.1177/1049732305281334

Ilies, L. \& Crișan, E. (2011). Managementul calității totale. Cluj-Napoca: Editura Risoprint.

Ilies, L., Mortan, M., Lungulescu, D., Lazăr, I., Popa, M. \& Vereș, V. (2006). Managementul firmei. Cluj-Napoca: Editura Risoprint.

Istocescu, A. (2003). Strategia si managementul strategic al firmei. București: Editura A.S.E.

Knight, F. H. (1921). Cost of production and price over long and short periods. Journal of Political Economy, University of Chicago Press, 29, p.304. 
Landes, D.S., Mokyr, J. \& Baumol W.J. (2010) (eds). The Invention of Enterprise: Entrepreneurship from Ancient Mesopotamia to Modern Times. Princeton: Princeton University Press

Marshall, A. (1922). Principles of Economics. $8^{\text {th }}$ edition reprinted. New York: Palgrave Macmillan.

McClelland, D.C. (1961). The achieving society. Van Nostrand.

Merriam, A. P. (1964). The Anthropology of Music. United States of America, Northwestern University Press.

Patzelt, H. \& Shepherd, D.A. (2011) Recognizing Opportunities for Sustainable Development. Entrepreneurship Theory and Practice. 35(4), 631-652. doi:10.1111/j.1540-6520.2010.00386.x

Rager, K.B. (2008). Product Review: Narrative and the Practice of Adult Education. Adult Learning. 19(1-2), 32-32. doi:10.1177/104515950801900108

Roșca, S. (2020). Cultura - factor de dezvoltare durabilă în Europa. Plus, Moldova: Editura Institutului de Relaţii Internaţionale.

Sarasvathy, S.D. \& Venkataraman, S. (2011). Entrepreneurship as Method: Open Questions for an Entrepreneurial Future. Entrepreneurship Theory and Practice. 35(1), 113-135. doi:10.1111/j.1540-6520.2010.00425.x

Slaughter, S. \& Leslie, L.L. (2001). Expanding and Elaborating the Concept of Academic Capitalism. Organization.; 8(2):154-161. doi:10.1177/1350508401082003

Schumpeter, J. A. (1934). The Theory of Economic Development. Harvard Economic Studies

van Praag, H., Shubert, T., Zhao, C., \& Gage F.H. (2005) Exercise enhances learning and hippocampal neurogenesis in aged mice. Journal of Neuroscience. 25(38), 8680-8685, doi: 10.1523/JNEUROSCI.1731-05.2005. PMID: 16177036; PMCID: PMC1360197. 